(6) OPEN ACCESS

\title{
Sex differences in survival after myocardial infarction in Sweden, 1987-2010
}

\author{
Johanna Berg, ${ }^{1}$ Lena Björck, ${ }^{1,2}$ Susanne Nielsen, ${ }^{1,2}$ Georgios Lappas, ${ }^{1}$ \\ Annika Rosengren ${ }^{1}$
}

- Additional material is published online only. To view please visit the journal online (http://dx.doi.org/10.1136/ heartjnl-2016-310281).

${ }^{1}$ Department of Molecular and Clinical Medicine, Sahlgrenska Academy, University of Gothenburg, Gothenburg, Sweden

${ }^{2}$ Institute of Health and Care Sciences, University of Gothenburg, Gothenburg, Sweden

\section{Correspondence to} Dr Johanna Berg, Department of Medicine, Sahlgrenska University Hospital/Östra, SE0416 85 Göteborg, Sweden; johanna.berg@gu.se

Received 18 July 2016 Revised 15 June 2017 Accepted 20 June 2017 Published Online First 7 August 2017

\begin{abstract}
Objective In this nationwide study, we investigated age-specific and sex-specific trends in sex differences in survival after acute myocardial infarction (AMI), including deaths from coronary heart disease (CHD) that occurred outside hospital.
\end{abstract}

Methods Observational study in Sweden of 28-day and 1-year mortality among 658110 persons $(35.7 \%$ women) aged 35-84 years with a first-time CHD event 1987-2010 with data retrieved from the national Swedish death and hospital registries.

Results Age-adjusted 28-day case fatality decreased from $23.5 \%$ to $8.5 \%$ over the period ( $p<0.05$ ). In hospitalised cases, short-term survival in women aged 35-54 years compared with men of the same age was poorer, not changing appreciably over time (HRs for women relative to men $1.63(95 \% \mathrm{Cl} 1.28$ to 2.08$)$ at age $35-54$ years and $1.28(95 \% \mathrm{Cl} 1.12$ to 1.46$)$ at age 55-64 years in 2005-2010), but after adjustment for comorbidities, differences between men and women were no longer significant (HR $1.25(95 \% \mathrm{Cl}$ 0.97 to 1.61$)$ and $1.05(95 \% \mathrm{Cl} 0.91$ to 1.20$))$. When CHD deaths outside hospital were included, women had better prognosis regardless of age and period. In patients surviving the first 28 days, age-adjusted 1 -year case fatality decreased from $15.3 \%$ to $7.7 \%$ $(p<0.05)$ for both men and women. After adjustment for comorbidities, no significant sex differences persisted below the age of 75 years in the last period. Female 28day survivors 75-84 years old had a consistently better prognosis than older men.

Conclusions The worse short-term outcomes in women $<55$ years of age hospitalised with AMI did not persist after adjustment for comorbidities. When CHD deaths outside hospital were included, women had consistently better short-term prognosis. In 28-day survivors, women did not fare worse than men when differences in comorbidities were considered.

\section{INTRODUCTION}

Young but not older women hospitalised with acute myocardial infarction (AMI) have been reported to have a worse prognosis than men. ${ }^{1-4}$ However, out-of-hospital deaths account for the absolute majority of all deaths from coronary heart disease $(\mathrm{CHD})^{5}$ but are commonly disregarded when comparing short-term prognosis in men and women after an acute coronary event.

Much of the research on sex differences in survival after AMI is based on data collected decades ago. There have been marked changes in treatment, clinical presentation, diagnostic criteria and prognosis after AMI. An earlier study found that women, particularly younger women, experienced greater improvements in hospital mortality after AMI than men, largely because of temporal changes in comorbidity and clinical severity features at admission. ${ }^{1}$ As a result, sex differences in shortterm case fatality decreased but did not disappear. However, in ST-elevation AMI (STEMI), the most severe form of AMI, gender differences in the use of evidence-based therapies and short-term survival in Sweden did not decline, ${ }^{6}$ although long-term risk of death was higher in men. ${ }^{7}$ Whether this applies to all myocardial infarctions in younger patients, if differences persist after taking comorbidities into account and if younger women fare worse when fatal events outside hospital are included remain unclear.

The linked Swedish person-based hospital and death registries offer unique opportunities to analyse gender differences in in-hospital and out-of-hospital mortality after a coronary event. The objective of this nationwide study, therefore, was to investigate past and current sex differences in survival after AMI in hospitalised cases, but also including deaths from CHD that occurred outside hospital.

\section{METHODS}

Sweden has a publicly financed healthcare system with hospital care available to all citizens at low cost. Swedish hospitals register principal and contributory discharge diagnoses for all patients in the national In-Patient Register (IPR). For the purpose of the present study, data from the IPR were linked with the national cause-specific death registry through the personal identity number, which is unique for all Swedish citizens. For confidentiality, all personal identity numbers were replaced by codes.

All persons in Sweden aged 35-84 years who had a first-time acute coronary event in the 24-year period, 1987 to 2010, were included, defined as either hospitalisation for AMI (International Classification of Diseases, Ninth Revision (ICD-9) code 410 for 1987 to 1996 and International Classification of Diseases, Tenth Revision (ICD-10) code I21 for 1997 and after) or CHD death (ICD-9 codes 410-414 for 1987 to 1996 and ICD-10 codes I20I25 after 1996) outside hospital. The population was divided into four age groups; $35-54$ years, 55-64 years, 65-74 years and 75-84 years. The
To cite: Berg J, Björck L, Nielsen $S$, et al. Heart 
28-day case fatality and the 1-year all-cause mortality were evaluated in four 6-year periods: 1987-1992, 1993-1998, 19992004 and 2005-2010.

The following comorbidities prior to the index hospitalisation were included in the adjusted analyses: diabetes (ICD-9 250 and ICD-10 E10-14), hypertension (ICD-9 401-405 and ICD-10 I10-I15), stroke (ICD-9 430-434, 436 and ICD-10 I60-I64), CHD (except AMI) (ICD-9 411-414 and ICD-10 I20, I22-I25), heart failure (HF) (ICD-8 427.10, 427.0; ICD-9 428A, 428B and 428X; ICD-10 I50), atrial fibrillation (ICD-8 427.92, ICD-9 427D and ICD-10 I48), chronic obstructive respiratory disease (ICD-8 and ICD-9 490-496, ICD-10 J44-J45), percutaneous coronary intervention (PCI) (ICD-9 3080 and ICD-10 FNG 00, FNG02, FNG 05), renal insufficiency (ICD-8 581, 583, 584; ICD-9 584-586; ICD-10 N17-N19) and malignancy (ICD-8 and ICD-9 140-208, ICD-10 C00-C97). Comorbidities were also registered, including the index hospitalisation for diabetes, hypertension, chronic respiratory disease, PCI and renal insufficiency, which means that persons included because of CHD death outside hospital had less chance of having a registered diagnosis of, for example, diabetes or hypertension. In the younger age groups, the autopsy rates were higher than among older persons. Swedish law requires an autopsy to be done if the cause of death is unclear, which means that if someone with no prior history of CHD dies suddenly or is found dead, an underlying cause of death will nearly be based on an autopsy. When autopsies are not performed, cause of death will be based on information from medical charts and previous history. Some degree of misclassification is obviously inevitable but is likely to be minor and not affect our findings more than to a very minor degree.

The study was approved by the regional Ethics Board of Gothenburg, Sweden.

\section{Statistical analysis}

Counts, proportions and mean values are presented and analysed by sex and hospitalisation status (in/out), within age groups and totally. $\mathrm{p}$ values for age differences between men and women were estimated with independent-samples t-test. Corresponding $\mathrm{p}$ values for differences in comorbidities were estimated with a $\chi^{2}$ test. The $\chi^{2}$ tests were corrected with the Yates's correction for continuity. All p values were two sided. Short-term (28-day) and long-term (from day 29 to day 365) case fatality count and percentages are presented for men and women by time period, for AMI cases admitted to hospital and/or for CHD death outside hospital. Short-term case fatality was analysed within the day of event. Corresponding HRs for women compared with men and their 95\% CIs, adjusted for baseline characteristics, were estimated with the Cox proportional hazards regression model. The 28-day case fatality was both analysed separately for patients admitted to hospital with a first AMI and also including patients with out-of-hospital CHD events. The statistics were computed with the aid of the IBM SPSS Statistics package version 21. Forest plots were constructed in Microsoft Excel 2013 and then converted to tiff.

\section{RESULTS}

\section{Baseline characteristics of patients}

During the 24 -year study period, 470420 patients aged 35 to 84 years were admitted to hospital with a first AMI, and 187690 patients had a fatal CHD event outside hospital without prior AMI; there were 234651 women and 423459 men, in total 658110 persons. The mean age was 68.3 years for men and 72.7 years for women in hospital and 71.9 versus 75.9 years for men and women out of hospital; thus, women were on average 4 years older than men. Women had more diabetes, hypertension, stroke, HF, chronic respiratory disease and malignancy, whereas men had more CHD. Women also had more atrial fibrillation overall, but this was confounded by age because women were older than men in this study, and among the three younger age groups, men had more atrial fibrillation (table 1 ; online supplement 1 , eTable 1 and online supplement 1 , eTable 2). Age-specific and period-specific descriptive data are provided in online supplement 1 eTable 1 and online supplement 1 , eTable 2. Among the younger adults, 35-54 years, women in and outside hospital had more diabetes, hypertension, stroke, chronic respiratory disease, renal insufficiency and malignancy concurrent with their acute coronary event compared with men. There were no significant sex differences in age or CHD, but more men had atrial fibrillation. Among the hospitalised individuals, women also had significantly more HF. Largely similar patterns were observed for middle-aged adults, 55-64 and 65-74 years. In the oldest group, 75-84 years, men admitted to hospital had more stroke, CHD and malignancy. Older men with fatal CHD events outside hospital in addition had more CHD, atrial fibrillation,

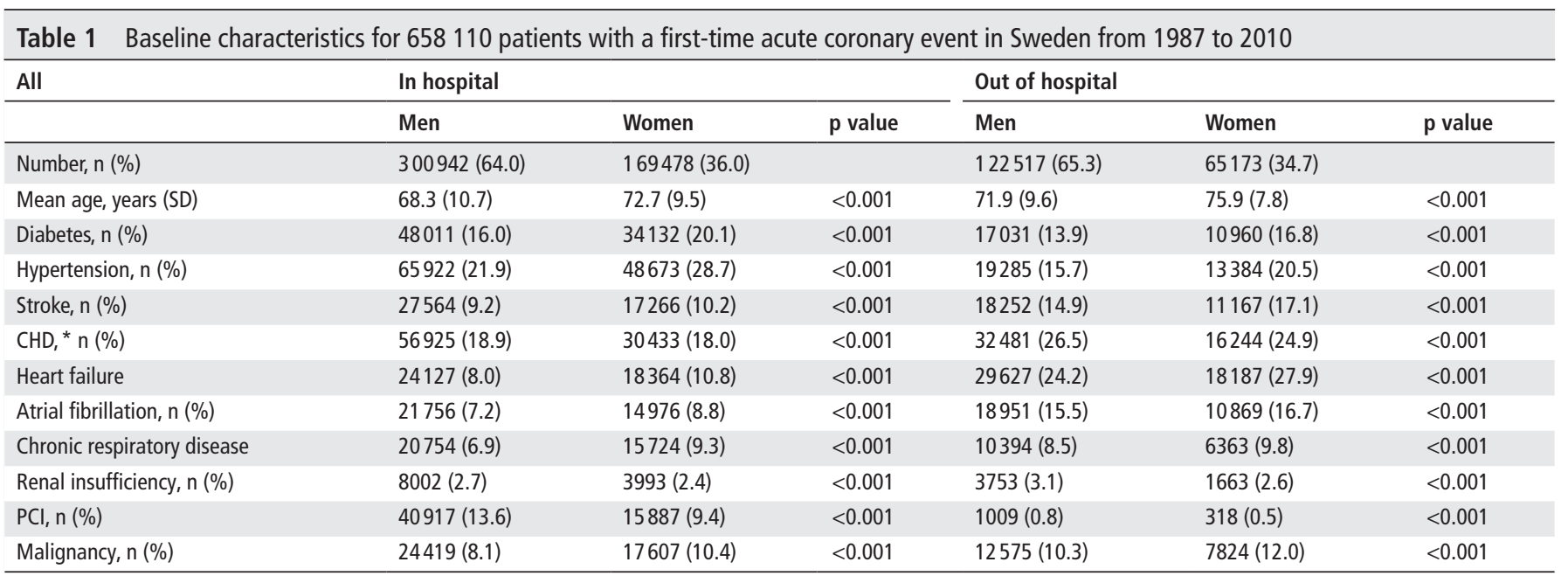

${ }^{*}$ Any CHD diagnosis except AMI.

$\mathrm{AMI}$, acute myocardial infarction; $\mathrm{CHD}$, coronary heart disease; $\mathrm{PCl}$, percutaneous coronary intervention. 


\begin{tabular}{|c|c|c|c|c|c|}
\hline & & Age adjusted & Multi adjusted & Men n (\%) & Women n (\%) \\
\hline \multicolumn{6}{|l|}{ Age $35-54$} \\
\hline $1987-1992$ & $\longmapsto-1$ & $1.52(1.30-1.78)$ & $1.27(1.08-1.49)$ & $617(6.21)$ & $203(9.33)$ \\
\hline $1993-1998$ & $\longmapsto-1$ & $1.55(1.29-1.86)$ & $1.37(1.14-1.65)$ & $432(4.26)$ & $157(6.58)$ \\
\hline $1999-2004$ & $\longmapsto-1$ & $1.49(1.23-1.80)$ & $1.26(1.04-1.54)$ & $338(3.72)$ & $148(5.48)$ \\
\hline $2005-2010$ & $\longmapsto-1$ & $1.63(1.28-2.08)$ & $1.25(0.97-1.61)$ & $195(2.28)$ & $96(3.68)$ \\
\hline \multicolumn{6}{|l|}{ Age $55-64$} \\
\hline $1987-1992$ & $1-1$ & $1.24(1.14-1.35)$ & $1.15(1.05-1.26)$ & $1837(11.10)$ & $712(13.90)$ \\
\hline 1993-1998 & $1--1$ & $1.12(1.01-1.26)$ & $1.05(0.94-1.18)$ & $1178(8.18)$ & $433(9.37)$ \\
\hline $1999-2004$ & $\mapsto-1$ & $1.41(1.25-1.59)$ & $1.29(1.14-1.46)$ & $824(5.27)$ & $403(7.48)$ \\
\hline $2005-2010$ & $1=-1$ & $1.28(1.12-1.46)$ & $1.05(0.91-1.20)$ & $743(4.39)$ & $315(5.65)$ \\
\hline \multicolumn{6}{|l|}{ Age $65-74$} \\
\hline $1987-1992$ & $\boldsymbol{m}$ & $1.03(0.99-1.08)$ & $1.01(0.97-1.06)$ & $5938(20.27)$ & $3170(21.33)$ \\
\hline $1993-1998$ & $\forall=1$ & $1.07(1.02-1.13)$ & $1.06(1.01-1.12)$ & $3850(15.58)$ & $2186(16.91)$ \\
\hline $1999-2004$ & $b=1$ & $0.98(0.92-1.05)$ & $0.97(0.91-1.03)$ & $2520(11.62)$ & $1342(11.61)$ \\
\hline $2005-2010$ & F멍 & $1.00(0.92-1.09)$ & $0.96(0.88-1.04)$ & $1618(7.90)$ & $826(8.12)$ \\
\hline \multicolumn{6}{|l|}{ Age $75-84$} \\
\hline $1987-1992$ & H & $0.93(0.90-0.96)$ & $0.93(0.90-0.96)$ & $8645(32.87)$ & $7354(31.55)$ \\
\hline $1993-1998$ & $\mathbf{H}$ & $0.95(0.91-0.98)$ & $0.97(0.93-1.00)$ & $6919(26.97)$ & $5762(26.24)$ \\
\hline $1999-2004$ & H & $0.93(0.89-0.97)$ & $0.95(0.92-0.99)$ & $5807(20.66)$ & $4769(19.72)$ \\
\hline \multirow[t]{2}{*}{$2005-2010$} & $\boldsymbol{H}$ & $0.92(0.88-0.97)$ & $0.94(0.90-0.99)$ & $5807(20.66)$ & $4769(19.72)$ \\
\hline & $\begin{array}{l}1 \\
1\end{array}$ & & & & \\
\hline
\end{tabular}

Figure 1 Twenty-eight-day age-adjusted case fatality (\%) and HRs for women compared with men after hospital admission for acute myocardial infarction in Sweden 1987-2010. Age adjusted and multiadjusted for age, diabetes, hypertension, stroke, heart failure, atrial fibrillation, chronic respiratory disease, percutaneous coronary intervention, renal insufficiency and malignancy. For every HR, the group of men are set as a reference in each period and age group.

chronic respiratory disease, renal insufficiency and malignancy. Women were older and had more diabetes and hypertension. More men underwent PCI.

\section{Twenty-eight-day survival}

In the hospitalised population, short-term survival improved markedly over the study period with an overall decrease of the proportion of both men and women dying within 28 days of admission to hospital from $23.5 \%$ to $8.5 \%(p<0.05)$. For men admitted to hospital, the overall case fatality was $9 \%$ in the last period 2005-2010 compared with 21\% from 1987 to 1992, with corresponding figures for women $11 \%$ and $25 \%$ (not shown). However, comparing women and men stratified for age revealed no improvement in the mortality gap between women and men. The largest difference was found in younger patients (35-54 years) with a largely unchanged age-adjusted HR compared with men of 1.63 (95\% CI 1.28 to 2.08 ) in the last 6-year period. However, the multivariable-adjusted HR of 1.25 (95\% CI 0.97 to 1.61 ) was not significantly elevated. For women 55-64 years old, the age-adjusted HR compared with men in the last period was 1.28 (95\% CI 1.12 to 1.46$)$, which was reduced to 1.05 (95\% CI 0.91 to 1.20 ) after adjustment for comorbidities. For those aged 65-74 years, the survival was similar for men and women. From 75 years, women had a better prognosis than men, multiadjusted HR 0.94 (95\% CI 0.90 to 0.99 ) in the last period (figure 1; online supplement 1), but again with no change over time.
Of all persons dying from CHD outside hospital, 65\% were men. When all cases of fatal CHD events outside hospital were added to the hospitalised AMI cases, men had an overall worse short-term prognosis. The age-adjusted HR for women compared with men was 0.88 (95\% CI 0.79 to 0.98 ) for those aged 35 to 54 years and 0.87 (95\% CI 0.85 to 0.90 ) in the oldest age group from 2005 to 2010 . In a model adjusted for multiple comorbidities, the age-adjusted HR for women compared with men was 0.72 (95\% CI 0.64 to 0.80 ) for patients from 35 to 54 years. In the oldest group from 75 to 84 years, the multiadjusted HR for women compared with men was 0.89 (95\% CI 0.87 to 0.92) (figure 2; online supplement 3).

\section{Long-term survival}

The overall long-term prognosis from day 29 to day 365 improved over the period from $15.3 \%$ to $7.7 \%(\mathrm{p}<0.05)$. The total mortality for women from days 29 to 365 after their myocardial infarction was $10.4 \%$ during the period 2005 to 2010 compared with $16.0 \%$ during the first period 1987 to 1992 . For men, the long-term case fatality decreased from $12.7 \%$ to $7.9 \%$ $(p<0.05)$. Age-specific 1-year survival improved for both men and women $(p<0.05)$. Age-adjusted long-term mortality was higher among women below 75 years, compared with men of the same age, in the last period 2005-2010, but after adjustment for comorbidities, there were no significant gender differences. Among the oldest age groups, men had higher mortality than women (figure 3; online supplement 3). 


\begin{tabular}{|c|c|c|c|c|c|}
\hline & & Age adjusted & Multi adjusted & Men n (\%) & Women n (\%) \\
\hline \multicolumn{6}{|l|}{ Age $35-54$} \\
\hline $1987-1992$ & $H=-1$ & $1.01(0.93-1.10)$ & $0.96(0.88-1.05)$ & $2873(23.57)$ & $618(23.86)$ \\
\hline 1993-1998 & $1=-1$ & $0.92(0.84-1.01)$ & $0.91(0.83-1.00)$ & $2659(21.51)$ & $556(19.96)$ \\
\hline $1999-2004$ & $F=-1$ & $0.89(0.81-0.97)$ & $0.82(0.75-0.91)$ & 2107 (19.41) & $533(17.27)$ \\
\hline $2005-2010$ & $1-1$ & $0.88(0.79-0.98)$ & $0.72(0.64-0.80)$ & $1613(16.16)$ & $419(14.30)$ \\
\hline \multicolumn{6}{|l|}{ Age 55-64 } \\
\hline $1987-1992$ & $\boldsymbol{H}$ & $0.93(0.89-0.98)$ & $0.92(0.88-0.97)$ & 7439 (33.58) & $2074(31.98)$ \\
\hline $1993-1998$ & $\mathbf{H}$ & $0.88(0.83-0.93)$ & $0.86(0.82-0.91)$ & $5480(29.30)$ & $1489(26.22)$ \\
\hline $1999-2004$ & $y=1$ & $0.90(0.85-0.96)$ & $0.87(0.82-0.93)$ & $4846(24.64)$ & $1454(22.57)$ \\
\hline $2005-2010$ & $b=1$ & $0.92(0.87-0.98)$ & $0.82(0.77-0.88)$ & $4546(21.93)$ & $1357(20.52)$ \\
\hline \multicolumn{6}{|l|}{ Age $65-74$} \\
\hline $1987-1992$ & H & $0.88(0.86-0.90)$ & $0.88(0.86-0.91)$ & $19681(45.73)$ & $8322(41.58)$ \\
\hline $1993-1998$ & $\mathbf{H}$ & $0.88(0.85-0.90)$ & $0.90(0.87-0.93)$ & $14765(41.44)$ & $17190(37.51)$ \\
\hline $1999-2004$ & $\mathbf{H}$ & $0.85(0.82-0.88)$ & $0.86(0.83-0.89)$ & $10079(34.45)$ & $4376(29.99)$ \\
\hline $2005-2010$ & $\mathbf{H}$ & $0.85(0.81-0.88)$ & $0.83(0.80-0.87)$ & $7983(29.73)$ & $3238(25.73)$ \\
\hline \multicolumn{6}{|l|}{ Age $75-84$} \\
\hline $1987-1992$ & H & $0.91(0.90-0.93)$ & $0.93(0.91-0.94)$ & $26739(60.23)$ & $21501(57.40)$ \\
\hline $1993-1998$ & $\|$ & $0.93(0.91-0.95)$ & $0.95(0.94-0.97)$ & $23502(55.64)$ & $18550(53.38)$ \\
\hline $1999-2004$ & H & $0.91(0.89-0.93)$ & $0.93(0.91-0.96)$ & $19023(46.03)$ & $14743(43.16)$ \\
\hline \multirow[t]{2}{*}{$2005-2010$} & H & $0.87(0.85-0.90)$ & $0.89(0.87-0.92)$ & $19023(46.03)$ & $14743(43.16)$ \\
\hline & 1 & & & & \\
\hline
\end{tabular}

Figure 2 Twenty-eight-day age-adjusted case fatality (\%) and HRs for women compared with men for all first acute coronary events (hospital admission for acute myocardial infarction or acute coronary death outside hospital) in Sweden from 1987 to 2010. Age adjusted and multiadjusted for age, diabetes, hypertension, stroke, heart failure, atrial fibrillation, chronic respiratory disease, percutaneous coronary intervention, renal insufficiency and malignancy. For every HR, the group of men are set as a reference in each period and age group.

\section{DISCUSSION}

Our large nationwide cohort describes current gender differences in short-term and long-term prognosis among patients with acute coronary events in Sweden, avoiding selection biases that may be present in selected hospital study populations. Although we observed an improved overall survival after AMI over the last two decades, the worse short-term outcomes in younger but not older women hospitalised with AMI persisted. The difference was, however, no longer significant when adjusted for comorbidities. Furthermore, when fatal CHD events occurring outside hospital were included, women in all age groups had a better prognosis, with between $10 \%$ and $20 \%$ lower mortality than men. Continuing mortality in patients surviving the first 28 days was no different in younger women compared with men of the same age, when comorbidities were taken into account.

After the landmark study by Vaccarino et $a l,{ }^{3}$ several studies have investigated sex differences in mortality in men and women. Gan et al found that the difference in short-term survival could be explained by differences in treatment. ${ }^{8}$ In a German study examining patients with STEMI, women received less aggressive treatment. ${ }^{9}$ Possible motives for less extensive treatment could, however, be that women tend to have less severe coronary artery disease although they have more risk factors than men. ${ }^{10}$ In Sweden, a delay has been observed for women with chest pain regarding admission to coronary care unit (CCU), medical treatment and coronary angiography. ${ }^{11}$ Being treated in a CCU is related to increased survival, but men have still been shown to have a lower case fatality both in CCUs and in medical wards. ${ }^{12}$ In addition, women with STEMI have been shown to receive less reperfusion and secondary preventive treatment. ${ }^{6}$
Even so, another study found no sex difference in the intensity of care among patients with non-ST-elevation acute coronary syndromes (NSTEMI). ${ }^{13}$ In contrast to the more recent findings by Vaccarino et al, ${ }^{1}$ where women experienced greater improvements in mortality when hospitalised for MI than men, and where the higher mortality rates of younger women with MI compared with men, as described in earlier years, narrowed considerably, our results differed in that we did not find any major change over the 24-year period in any age group. Even so, their comorbidity-adjusted female to male ratio of hospital mortality in patients $<55$ years in 2004-2006 was 1.48 , which is not markedly different to our figure of 1.25 for 2005-2010.

Some studies have found that the worse prognosis in women, compared with men, in the hospitalised population may be due to an increasing probability of surviving to reach hospital, and that men overall actually have a worse prognosis. A large study from Scotland was concordant with our results, confirming a worse short-term prognosis for men if all fatal AMI cases were included. ${ }^{14}$ Low socioeconomic status (SES) and deprivation have been shown to increase risk for both CHD incidence and out-of-hospital death in men and women. SES needs to be considered in primary and secondary prevention. ${ }^{15}$ As more sensitive biochemical markers and new diagnostic criteria were introduced, smaller and potentially less severe infarctions are now detected. ${ }^{16}$ Further developments of these criteria were published in $2007^{17}$ and $2012,^{18}$ with myocardial infarction subdivided in five main types. Increased diversity within the AMI diagnosis as well as new criteria probably also have had impact on the total incidence and case fatality. The proportion of STEMI has decreased, and the NSTEMI proportion has 


\begin{tabular}{|c|c|c|c|c|c|}
\hline & & Age adjusted & Multi adjusted & Men n (\%) & Women n (\%) \\
\hline \multicolumn{6}{|l|}{ Age $35-54$} \\
\hline $1987-1992$ & $\longmapsto-1$ & $1.46(1.15-1.86)$ & $1.12(0.87-1.44)$ & $280(3.0)$ & $86(4.4)$ \\
\hline $1993-1998$ & $\longmapsto-1$ & $1.08(0.80-1.44)$ & $0.91(0.67-1.22)$ & $226(2.3)$ & $56(2.5)$ \\
\hline $1999-2004$ & $\longmapsto$ & $1.27(0.93-1.74)$ & $0.99(0.72-1.36)$ & $146(1.7)$ & $54(2.1)$ \\
\hline $2005-2010$ & $\longmapsto$ & $1.33(0.91-1.93)$ & $0.88(0.60-1.30)$ & $97(1.2)$ & $38(1.5)$ \\
\hline \multicolumn{6}{|l|}{ Age $55-64$} \\
\hline 1987-1992 & $\mapsto-1$ & $1.08(0.94-1.24)$ & $0.96(0.84-1.10)$ & $855(5.81)$ & $283(6.41)$ \\
\hline $1993-1998$ & $\mapsto-1$ & $1.12(0.95-1.32)$ & $1.00(0.85-1.18)$ & $553(4.18)$ & $203(4.84)$ \\
\hline $1999-2004$ & $\mapsto-1$ & $1.18(1.00-1.38)$ & $0.99(0.84-1.16)$ & $519(3.50)$ & $212(4.25)$ \\
\hline $2005-2010$ & $\mapsto-1$ & $1.43(1.21-1.68)$ & $1.09(0.92-1.29)$ & $452(2.79)$ & $212(4.03)$ \\
\hline \multicolumn{6}{|l|}{ Age $65-74$} \\
\hline 1987-1992 & $\mathrm{F}=1$ & $0.94(0.89-1.01)$ & $0.90(0.84-0.95)$ & $2885(12.35)$ & $1409(12.05)$ \\
\hline $1993-1998$ & $F=1$ & $0.90(0.83-0.97)$ & $0.86(0.79-0.93)$ & $2030(9.73)$ & $972(9.05)$ \\
\hline $1999-2004$ & $1-1$ & $0.95(0.87-1.03)$ & $0.89(0.82-0.97)$ & $1645(8.58)$ & $851(8.33)$ \\
\hline $2005-2010$ & $H-1$ & $1.13(1.03-1.24)$ & $1.01(0.92-1.11)$ & $1186(6.29)$ & $687(7.35)$ \\
\hline \multicolumn{6}{|l|}{ Age $75-84$} \\
\hline 1987-1992 & H & $0.92(0.88-0.97)$ & $0.90(0.86-0.94)$ & $4224(23.92)$ & $3675(23.03)$ \\
\hline $1993-1998$ & $\mathbf{H}$ & $0.90(0.86-0.95)$ & $0.92(0.88-0.97)$ & 3734 (19.93) & $3025(18.67)$ \\
\hline $1999-2004$ & 怕 & $0.88(0.84-0.92)$ & $0.89(0.85-0.93)$ & $4214(18.90)$ & $3379(17.41)$ \\
\hline \multirow[t]{2}{*}{$2005-2010$} & 标 & $0.90(0.85-0.95)$ & $0.88(0.84-0.93)$ & $4214(18.90)$ & $3379(17.41)$ \\
\hline & $\begin{array}{l}1 \\
1\end{array}$ & & & & \\
\hline
\end{tabular}

Figure 3 Age-adjusted case fatality (\%) and HRs after acute myocardial infarction for adults aged 35-84 years from days 29 to 365 in Sweden from 1987 to 2011. Age adjusted and multiadjusted for age, diabetes, hypertension, stroke, heart failure, atrial fibrillation, chronic respiratory disease, percutaneous coronary intervention, renal insufficiency and malignancy. For every HR, the group of men are set as a reference in each period and age group.

increased. Because STEMI is more common among men and younger age groups and is related to early case fatality, ${ }^{19}$ this could contribute to explain the higher out-of-hospital mortality in men, with a higher proportion of large and potentially immediately fatal events. The incidence of AMI has not decreased among women below 65 years to the same extent as for men, ${ }^{20}$ but the potentially increased detection and labelling of coronary events as AMIs could be at play here.

The majority of coronary deaths, or nearly four out of five of all deaths, occur outside hospital. ${ }^{5}$ We have previously shown that as in-hospital deaths declined faster than deaths outside hospital, the relative contribution of out-of-hospital deaths to overall case fatality has increased. Accordingly, when analysing case fatality for acute coronary events, in-hospital deaths represent only a minority of all fatalities. Still, because in-hospital mortality may be improved by more optimal management, sex differences in in-hospital mortality are not unimportant. The continuing poorer survival in younger women hospitalised with AMI, which is largely due to their higher burden of comorbidities, warrants further investigation.

\section{Strengths and limitations of this study}

The strengths of the study include nationwide coverage with virtually no loss to follow-up and the large sample size. The study covers all patients in Sweden with a first-time major coronary event occurring within the last 24 years and accordingly reflects the national trends in CHD prognosis. We also included the out-of-hospital fatal cases and analysed possible confounding factors. Both short-term and long-term trends were examined.
All fatal CHD events and not only fatal AMI were considered for the out-of-hospital cases to represent a more correct estimate of coronary deaths.

Limitations concerning administrative registers are lack of information regarding comorbidities diagnosed in the primary healthcare; interventional or medical interventions prior to the event or in hospital; no details of clinical characteristics, such as biomarkers, electrocardiographic or autopsy findings; potential misclassification of diagnoses; and no uniform criteria for diagnosis over time. Nevertheless, validation studies indicate reasonable accuracy. In one study, the IPR was validated, and the positive predictive value for major diagnoses was $85 \%-95 \%$, but lower for important comorbidities such as hypertension or diabetes. ${ }^{21}$ Still, over $99 \%$ of all hospital discharges are included in the register. However, for the patients with fatal CHD events, there is a possibility that the undiagnosed comorbidity rates are higher than among the patients that were admitted to hospital. Second, the rate of autopsies has been decreasing, although autopsy is still mandatory in persons who die outside hospital without a clear diagnosis. However, autopsy rates for the present study population were quite high among persons with out-of-hospital deaths, overall $81 \%$ for persons $35-54$ years of age, $68 \%$ for those 55 to 64 years of age but only $49 \%$ for those 65 to 74 years of age. ${ }^{5}$ Misclassification of non-coronary deaths as CHD deaths is therefore probably relatively minor in the younger subset of our population but may obviously be higher among older persons, in whom autopsy rates were lower. Although data for all of Sweden were included, findings may not be applicable to other settings and must, furthermore, be seen 
against the background of markedly overall improved survival over time, where we lack the data to consider the relative importance of increasingly intense medical and interventional management and of potential changes in clinical presentation, with smaller infarctions and less STEMI.

\section{CONCLUSIONS}

The overall case fatality among the 658110 persons with AMI in our study decreased from 1987 to 2011 in all age groups. Women below 65 years of age, hospitalised with AMI, still have a higher 28-day case fatality than men. However, when including fatal CHD events occurring outside hospital, men have a higher short-term case fatality in all age groups. One-year case fatality has decreased in both men and women, but women still have a poorer prognosis before the age of 75 years. Some of the poorer survival among women compared with men can be explained by comorbidities. Given the overall better survival in women, however, this means that younger women stand to lose more of their remaining potential life years than men. Treatment of comorbidities in women should probably receive more attention.

\section{Key messages}

\section{What is already known on this subject? \\ Younger women hospitalised with acute myocardial infarction (AMI) have previously had higher short-term case fatality than men of the same age.}

\section{What might this study add?}

Although we observed an improved overall survival after AMI over the last two decades, the worse short-term outcomes in women from 35 to 64 years but not women from 65 to 84 years hospitalised with AMI persisted. Younger, but not older, women hospitalised with AMI have higher short-term case fatality than men of the same age. The difference was, however, no longer significant when adjusted for comorbidities. When fatal coronary heart disease events occurring outside hospital were included, women at all ages had between $10 \%$ and $20 \%$ lower mortality compared with men.

\section{How might this impact on clinical practice?}

\section{If data on comorbidities are taken into account, women} hospitalised with AMI do not have a worse prognosis than men and fare slightly better when out-of-hospital fatal coronary events are considered. Treatment of comorbidities in women should probably receive more attention.

Contributors JB designed the study, performed the statistical analysis and prepared the manuscript. LB advised on the study design and interpretation of data. SN adviced on the interpretation of data. GL was responsible for data collection and statistical advice. AR advised on the study design and interpretation of data. All authors contributed to the study design, read, critically revised and approved the final manuscript.

Funding The study was financed by grants from the Swedish state, under the agreement between the Swedish government and the county councils concerning economic support of research and education of doctors (ALF agreement), the Health and Medical Care Committee of the Regional Executive Board, Region Västra Götaland, Sweden; the Swedish Heart and Lung Foundation (201500438); the Swedish Research Council $(201305187,201304236)$ and the Swedish Council for Health, Working Life and Welfare (FORTE) (200702280, 201300325).

Competing interests None declared.
Ethics approval The Regional Ethics Board of Gothenburg, Sweden.

Provenance and peer review Not commissioned; externally peer reviewed.

Open Access This is an Open Access article distributed in accordance with the Creative Commons Attribution Non Commercial (CC BY-NC 4.0) license, which permits others to distribute, remix, adapt, build upon this work non-commercially, and license their derivative works on different terms, provided the original work is properly cited and the use is non-commercial. See: http://creativecommons.org/ licenses/by-nc/4.0/

(C) Article author(s) (or their employer(s) unless otherwise stated in the text of the article) 2017. All rights reserved. No commercial use is permitted unless otherwise expressly granted.

\section{REFERENCES}

1 Vaccarino V, Parsons L, Peterson ED, et al. Sex differences in mortality after acute myocardial infarction: changes from 1994 to 2006. Arch Intern Med 2009;169:1767-74.

2 Rosengren A, Spetz CL, Köster M, et al. Sex differences in survival after myocardial infarction in Sweden; data from the Swedish National Acute Myocardial Infarction Register. Eur Heart J 2001;22:314-22.

3 Vaccarino V, Parsons L, Every NR, et al. Sex-based differences in early mortality after myocardial infarction. National Registry of Myocardial Infarction 2 Participants. N Eng/ J Med 1999:341:217-25.

4 Peltonen $M$, Lundberg V, Huhtasaari F, et al. Marked improvement in survival after acute myocardial infarction in middle-aged men but not in women. The Northern Sweden MONICA study 1985-94. J Intern Med 2000;247:579-87.

5 Dudas K, Lappas G, Stewart S, et al. Trends in out-of-hospital deaths due to coronary heart disease in Sweden (1991 to 2006). Circulation 2011;123:46-52.

6 Lawesson SS, Alfredsson J, Fredrikson M, et al. Time trends in STEMI-improved treatment and outcome but still a gender gap: a prospective observational cohort study from the SWEDEHEART register. BMJ Open 2012;2:e000726.

7 Lawesson SS, Alfredsson J, Fredrikson M, et al. A gender perspective on short- and long term mortality in ST-elevation myocardial infarction-a report from the SWEDEHEART register. Int J Cardiol 2013;168:1041-7.

8 Gan SC, Beaver SK, Houck PM, et al. Treatment of acute myocardial infarction and 30-day mortality among women and men. N Engl J Med 2000;343:8-15.

9 Heer T, Schiele R, Schneider S, et al. Gender differences in acute myocardial infarction in the era of reperfusion (the MITRA registry). Am J Cardiol 2002;89:511-7.

10 Dey S, Flather MD, Devlin G, et al. Global Registry of Acute Coronary Events investigators. Sex-related differences in the presentation, treatment and outcomes among patients with acute coronary syndromes: the Global Registry of Acute Coronary Events. Heart 2009;95:20-6.

11 Ravn-Fischer A, Karlsson T, Santos M, et al. Inequalities in the early treatment of women and men with acute chest pain? Am J Emerg Med 2012;30:1515-21.

12 Lundberg V, Wikström B, Boström S, et al. Exploring sex differences in case fatality in acute myocardial infarction or coronary death events in the northern Sweden MONICA Project. J Intern Med 2002;251:235-44.

13 Alfredsson J, Sederholm-Lawesson S, Stenestrand U, et al. Although women are less likely to be admitted to coronary care units, they are treated equally to men and have better outcome. A prospective cohort study in patients with non ST-elevation acute coronary syndromes. Acute Card Care 2009;11:173-80.

14 Maclntyre K, Stewart S, Capewell S, et al. Gender and survival: a population-based study of 201,114 men and women following a first acute myocardial infarction. J Am Coll Cardiol 2001;38:729-35.

15 Capewell S, Maclntyre K, Stewart S, et al. Age, sex, and social trends in out-ofhospital cardiac deaths in Scotland 1986-95: a retrospective cohort study. Lancet 2001;358:1213-7.

16 Alpert JS, Thygesen K, Antman E, et al. Myocardial infarction redefined--a consensus document of The Joint European Society of Cardiology/American College of Cardiology Committee for the redefinition of myocardial infarction. J Am Coll Cardiol 2000;36:959-69.

17 Thygesen K, Alpert JS, White HD. Universal Definition of Myocardial Infarction. J Am Coll Cardiol 2007;50:2173-95.

18 Thygesen K, Alpert JS, Jaffe AS, et al. Writing Group on the Joint ESC/ACCF/AHA/WHF Task Force for the Universal Definition of Myocardial InfarctionESC Committee for Practice Guidelines (CPG). Third universal definition of myocardial infarction. Eur Heart J 2012;33:2551-67.

19 Björck L, Rosengren A, Wallentin L, et al. Smoking in relation to ST-segment elevation acute myocardial infarction: findings from the Register of Information and Knowledge about Swedish Heart Intensive Care Admissions. Heart 2009;95:1006-11.

20 National Board of Health and Welfare. Public Health Report, 2013.

21 Ludvigsson JF, Andersson E, Ekbom A, et al. External review and validation of the Swedish national inpatient register. BMC Public Health 2011;11:450. 